\title{
Coinfection of SARS-CoV-2 and Measles morbillivirus in a front-line health worker in Rio de Janeiro, Brasil
}

Dacqueline Stephanie Fernandes do Nascimento
(iD) Renata R. T. Castro,4
(D) Janie Kelly Fernandes do Nascimento
(iD) Brunno Bastos Knoploch ${ }^{\mathbf{1}}$
(D) Patrícia Maria Carla Osório Duque
(iD) Marco Antônio Orsini Neves

1. Faculdade de Medicina, Universidade Iguaçu, Nova Iguaçu, RJ, Brasil. 2. Sistema Único de Saúde, Rio de laneiro, RJ, Brasil. 3. Universidade Estácio de Sá, Rio de Janeiro, RJ, Brasil. 4. Universidade Federal Fluminense, Niterói, RJ, Brasil.

http://dx.doi.org/10.1590/1806-9282.66.8.1027
KEYWORDS: Coronavirus Infections. Coinfection. Measles. Vaccines.

Healthcare workers (HCW) are at high risk of contracting the Coronavirus disease 2019 (COVID19), even with the use of personal protective equipment, due to the greater exposure, work intensity, lack of rest, inadequate training, and while undressing'. In China, at least 3,387 HCW were infected, with 22 deaths'. Sadly, numbers are still growing, but by March 2020, Italy had reported the infection of over 2,600 HCW and, in April, the United States estimated more than 9,200 infected HCW.

Currently, there are no vaccines or specific antiviral drugs for COVID-19. Its frequent mutations facilitate fast transmissibility and difficult the designing of a vaccine ${ }^{2}$. Vaccination exposes the body to antigens and activates the immune system without causing disease. However, even in a highly vaccinated population, outbreaks may still happen. In this letter, we describe a case of co-infection with SARS-CoV-2 and
Measles morbillivirus in a front-line health worker in Brasil. The case report was approved by the Ethics Research Committee on March 15, 2020, under the number 012342020. The patient signed an informed consent form.

\section{CASE}

A 25-year-old male caucasian physician with mild asthma history and not in use of any medication, fighting in the front-line against COVID-19, presented prostration, sleeping difficulty, and fever $\left(37.8^{\circ} \mathrm{C}\right)$, for which he took antipyretics and analgesics. On the following two days, he evolved with odynophagia, dysphagia, worsening of prostration, productive cough, and anosmia. On the $3^{\text {rd }}$ day, the patient reported dry cough and rhinorrhea. A nasopharyngeal swab was used and sent for RT-PCR COVID-19 testing. On the 
$5^{\text {th }}$ day, new symptoms were added (table 1): tachydyspnea, conjunctival hyperemia, morbilliform erythematous maculopapular non-itching rash on his face, trunk, limbs, and on the palms of both hands. (figure 1). A physical exam also revealed palpable lymph nodes in the bilateral occipital and spinal accessory chains and clustered white lesions on the buccal mucosa (Koplik's sign). Azithromycin 500mg, prednisone 20mg, antiemetic, antiallergic, and analgesic drugs were prescribed. On the next day, the patient presented desaturation and needed supplementary oxygen. Three days later, the patient had no rashes. The last symptoms to disappear were cough and anosmia (table).

RT-PCR were positive for COVID-19 and Measles morbilivirus. Serologies for measles were also positive
[IgG: $3687 \mathrm{mUI} / \mathrm{mL}$ (positive reference value $>200$ $\mathrm{mUI} / \mathrm{mL}$ ); IgM: $524 \mathrm{U} / \mathrm{mL}$ (positive reference value> $15 \mathrm{U} / \mathrm{mL}$ ). The patient reported vaccination with three doses of MMR vaccine during childhood.

\section{DISCUSSION}

Measles is a highly contagious disease and still a common threat in the underdeveloped world ${ }^{3}$. Live attenuated measles vaccine is considered to have high protective efficacy, especially after two doses (94\% efficacy $)^{4}$. In countries with high vaccine coverage, as in Brasil, measles outbreaks happen mainly due to importation or vaccination failure ${ }^{5}$. Nevertheless, the infection may happen in vaccinated patients due to suboptimal measles vaccine-induced humoral

TABLE 1. SYMPTOM TIMELINE

\begin{tabular}{|c|c|c|c|c|c|c|c|c|c|c|c|c|c|c|c|c|}
\hline Symptomatologic Chronology & \begin{tabular}{|c|}
$29 / 3$ \\
$D 1$
\end{tabular} & $\begin{array}{c}30 / 3 \\
D 2\end{array}$ & $\begin{array}{c}31 / 3 \\
D 3\end{array}$ & $\begin{array}{c}01 / 4 \\
D 4\end{array}$ & $\begin{array}{c}02 / 4 \\
D 5\end{array}$ & $\begin{array}{c}03 / 4 \\
D 6\end{array}$ & $\begin{array}{c}04 / 4 \\
\text { D7 }\end{array}$ & $\begin{array}{c}05 / 4 \\
\text { D8 }\end{array}$ & $\begin{array}{c}06 / 4 \\
D 9\end{array}$ & $\begin{array}{l}07 / 4 \\
\mathrm{D} 10\end{array}$ & $\begin{array}{l}08 / 4 \\
\text { D11 }\end{array}$ & $\begin{array}{l}09 / 4 \\
D 12\end{array}$ & $\begin{array}{l}10 / 4 \\
D 13\end{array}$ & $\begin{array}{l}11 / 4 \\
\text { D14 }\end{array}$ & $\begin{array}{l}12 / 4 \\
\text { D15 }\end{array}$ & $\begin{array}{l}13 / 4 \\
\text { D16 }\end{array}$ \\
\hline \multicolumn{17}{|l|}{ Prostration/ Nausea } \\
\hline \multicolumn{17}{|l|}{ Fever } \\
\hline \multicolumn{17}{|l|}{ Odinophagy } \\
\hline \multicolumn{17}{|l|}{ Cough } \\
\hline \multicolumn{17}{|l|}{ Anosmia } \\
\hline \multicolumn{17}{|l|}{ Ageusia } \\
\hline \multicolumn{17}{|l|}{ face edema } \\
\hline \multicolumn{17}{|l|}{ Skin rash/ Conjunctival hyperemia } \\
\hline \multicolumn{17}{|l|}{ Tachypnea } \\
\hline Desaturation & & & & & & & & & & & & & & & & \\
\hline
\end{tabular}

FIGURE 1. ERYTHEMATOUS MACULOPAPULAR RASH MORBILLIFORM ON THE FACE (A), TRUNK (B), AND HANDS (C).

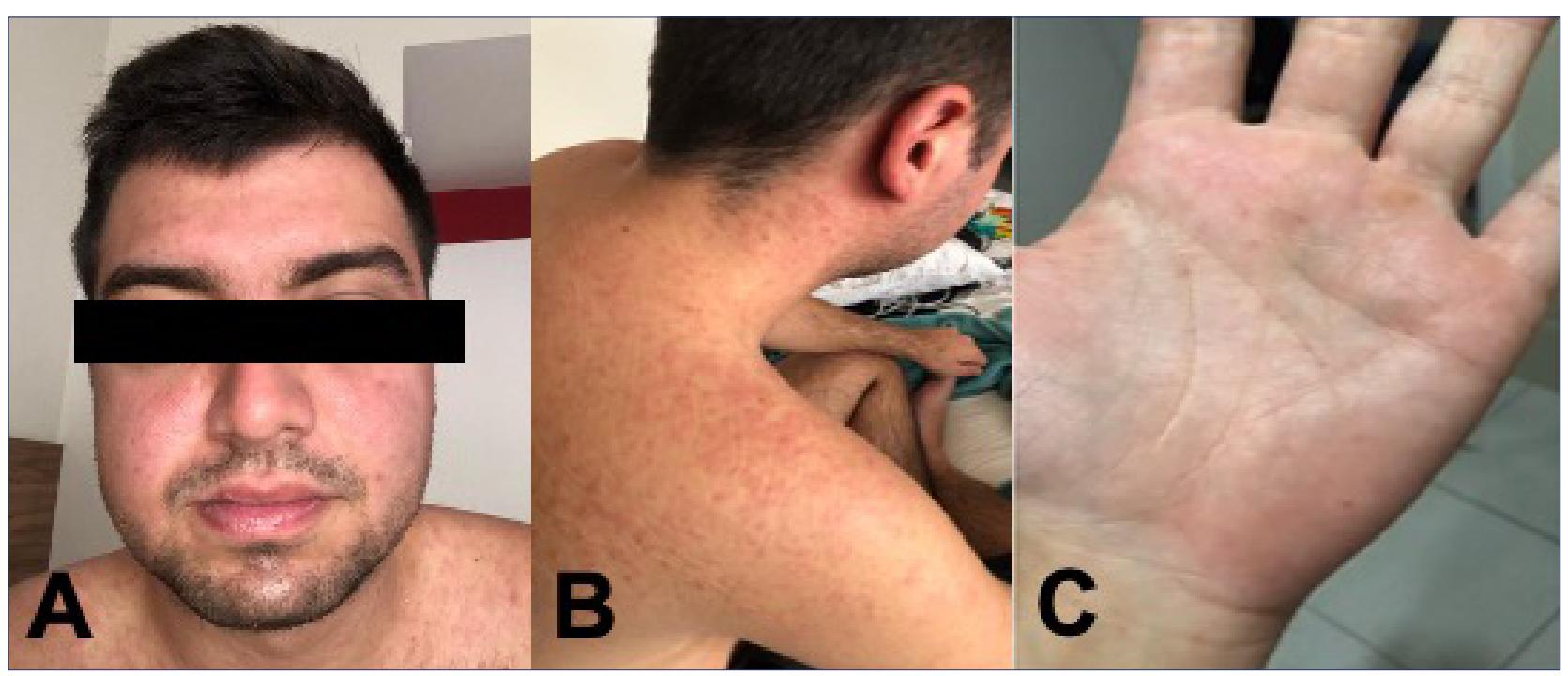


immunity and/or waning immunity in a low measles-exposure environment ${ }^{6}$.

Coronavirus and Measles morbillivirus have an evolutionary connection, as they share core proteins ${ }^{7}$. Measles vaccination may increase the ability of the immune system to fight COVID-197. Coinfections may facilitate genetic exchange and generate recombinant viruses, influencing viral evolution, sensitivity to antiviral therapy, and disease course ${ }^{8,9}$.

Our patient presented a relatively benign course of both infections, which may be explained by competitive suppression between the viruses. In this case, similar viruses interfere with the replication of one another or there may have been a competition between the viruses for metabolites, replication sites, or host factors necessary for virus replication ${ }^{8}$.

Physicians are trained to think of a single virus causing a clinical syndrome. During the pandemic, it is clear that COVID-19 is going to be the first diagnostic hypothesis for most respiratory syndromes. But we must be aware of the similarities between viruses. Future studies should increase the knowledge about how frequent coinfections happen and how they interfere in the disease course.

\section{Conflicts of Interest}

The authors declare no conflicts of interest.

\section{Funding}

This work did not receive any specific grant from funding agencies in the public, commercial, or notfor-profit sectors.

\section{Author's Contribution}

JSFN, JKFN, and MAON devised the project, the main conceptual ideas, and collected the data.

All authors worked on technical details, literature review, and discussion.

RRTC and MAON wrote the manuscript

\section{REFERENCES}

1. Wang J, Zhou M, Liu F. Reasons for healthcare workers becoming infected with novel coronavirus disease 2019 (COVID-19) in China. I Hosp Infect. 2020;105(1):100-1.

2. Yin C. Genotyping coronavirus SARS-CoV-2: methods and implications Genomics. 2020;50888-7543(20)30318-9.

3. Dabbagh A, Laws RL, Steulet C, Dumolard L, Mulders MN, Kretsinger K, et al. Progress toward regional measles elimination - worldwide, 2000-2017. MMWR Morb Mortal Wkly Rep. 2018;67(47):1323-9.

4. Uzicanin A, Zimmerman L. Field effectiveness of live attenuated measles-containing vaccines: a review of published literature. | Infect Dis. 2011;204(Suppl 1):S133-48.
5. Goldani LZ. Measles outbreak in Brasil, 2018. Braz | Infect Dis. 2018;22(5):359.

6. Haralambieva IH, Kennedy RB, Ovsyannikova IG, Schaid DI, Poland GA Current perspectives in aassessing humoral immunity after measles vaccination. Expert Rev Vaccines. 2019;18(1):75-87.

7. Saad ME, Elsalamony RA. Measles vaccines may provide partial protection against COVID-19. IJCBR. 2020;5(1):14-9.

8. Kumar N, Sharma S, Barua S, Tripathi BN, Rouse BT. Virological and immunological outcomes of coinfections. Clin Microbiol Rev. 2018;31(4):e00111-17.

9. Asner SA, Science ME, Tran D, Smieja M, Merglen A, Mertz D. Clinical disease severity of respiratory viral co-infection versus single viral infection: a systematic review and meta-analysis. PLoS One. 2014;9(6):e99392. 